\title{
Comparison of birth certificates and hospital-based birth data on pregnancy complications in Los Angeles and Orange County, California
}

\author{
Nekisa Haghighat ${ }^{1}$, Maogui Hu${ }^{1}$, Olivier Laurent ${ }^{1}$, Judith Chung ${ }^{2}$, Peter Nguyen ${ }^{3}$ and Jun Wu ${ }^{1 *}$
}

\begin{abstract}
Background: The incidence of both gestational diabetes mellitus and preeclampsia is on the rise; however, these pregnancy complications may not be systematically reported. This study aimed to examine differences in reporting of preeclampsia and gestational diabetes between hospital records and birth certificate data, and to determine if such differences vary by maternal socioeconomic status indicators.

Methods: We obtained over 70,000 birth records from 2001 to 2006 from the perinatal research database of the Memorial Care system, a network of four hospitals in Los Angeles and Orange Counties, California. Memorial birth records were matched to corresponding state birth certificate records and analyzed to determine differential rates of reporting of preeclampsia and diabetes. Additionally, the influence of maternal socioeconomic factors on the reported incidence of such adverse pregnancy outcomes was analyzed. Socioeconomic factors of interest included maternal education levels, race, and type of health insurance (private or public).

Results: It was found that the birth certificate data significantly underreported the incidence of both preeclampsia $(1.38 \%$ vs. $3.13 \%)$ and diabetes (1.97\% vs. $5.56 \%$ ) when compared to Memorial data. For both outcomes of interest, the degree of underreporting was significantly higher among women with lower education levels, among Hispanic women compared to Non-Hispanic White women, and among women with public health insurance.

Conclusion: The Memorial Care database is a more reliable source of information than birth certificate data for analyzing the incidence of preeclampsia and diabetes among women in Los Angeles and Orange Counties, especially for subpopulations of lower socioeconomic status.
\end{abstract}

Keywords: Birth certificates, Hospital birth records, Preeclampsia, Diabetes, Socioeconomic status

\section{Background}

Adverse pregnancy outcomes such as gestational diabetes mellitus and preeclampsia have important consequences on the growth, development, and health of children and mothers alike. Gestational diabetes mellitus is defined as carbohydrate intolerance with onset or recognition during pregnancy [1]. The true prevalence of gestational diabetes is unknown, with estimates ranging from 1 to $14 \%$ of

\footnotetext{
* Correspondence: junwu@uci.edu

'Program in Public Health, College of Health Sciences, University of California, Anteater Instruction \& Research Bldg (AIRB) \# 2034, 653 East Peltason Drive, Irvine, CA 92697-3957, USA

Full list of author information is available at the end of the article
}

pregnancies affected in the United States annually [2-4]. Preeclampsia is a pregnancy complication that is characterized by the onset of hypertension and the presence of protein in the urine at $>20$ weeks gestation in a previously normotensive woman [5]. It is estimated to have affected $3.8 \%$ of US deliveries in 2010, with the rate of severe preeclampsia rapidly increasing over the past three decades [6].

Despite the fact that the incidence of both gestational diabetes and preeclampsia is on the rise, there is concern that these and other pregnancy complications are not systematically recognized, diagnosed, or reported. In fact, numerous studies have found significant inconsistency 
between medical information that is reported on birth certificates and other medical records such as hospitaldischarge records. A recent study found that in Washington State, most pregnancy complications in general, and gestational diabetes in particular, are substantially underreported on birth certificates compared to hospital-discharge data [7]. Another study conducted in Ohio discovered that birth certificate data was less reliable than hospital records for identifying maternal risk factors, comorbid conditions, and complications of pregnancy, labor, and delivery [8]. Moreover, a number of other studies have discovered underreporting of birth defects [9], delivery complications [10], and other standard measures taken at birth [8] using state birth certificates alone. A review of the current literature suggests that birth certificates are generally not reliable sources of information on tobacco and alcohol use, prenatal care, maternal risk, pregnancy complications, labor, and delivery [11].

In addition to the question of systematic underreporting of adverse pregnancy outcomes, there is considerable interest in determining if this underreporting varies according to socioeconomic status. The socioeconomic gradient in preeclampsia is well established, with more recent data suggesting that there is a significant negative association between socioeconomic status and preeclampsia. Studies have found such an association using maternal education level [12], census tract income level [13], and household income level [5] as socioeconomic indicators. However, inconsistent findings have also been reported, with older studies finding no association between low socioeconomic status and preeclampsia [14-16].

Studies that have investigated the association between socioeconomic status and gestational diabetes, however, have generated conflicting results that vary according to the socioeconomic indicators used. Numerous studies have found low socioeconomic status to be associated with a higher risk of gestational diabetes using maternal employment status [17], neighborhood income level $[18,19]$, education level $[20,21]$, type of hospital services used [22], and family income level [23, 24] as socioeconomic indicators. In contrast, a study that measured a combination of indicators including maternal employment status, education level, parity, and monthly income level, found no association between low socioeconomic status and gestational diabetes [25]. Other studies have also found no association using neighborhood deprivation level [26], insurance status [27], and level of maternal education [28] as markers.

It has not yet been determined if the discrepancies in the results of these studies may be accounted for by differential reporting rates among populations of varying socioeconomic levels, a feature that may vary across study settings. Additionally, the reliability of California's birth certificate registry compared to available medical records has yet to be determined. Thus, this paper examines the possibility of underreporting of adverse pregnancy outcomes in patients in Los Angeles County and Orange County, California, using data from both birth certificates and hospital birth records, with a specific focus on possible differential rates of underreporting according to socioeconomic status.

\section{Methods \\ Birth record data}

Birth record data from the period of 2001 to 2006 were obtained from the Memorial Care System, a network of four hospitals that maintains a perinatal database for research purposes [29]. Records are inputted into this database by nurses when patients are admitted to the hospital for delivery. The four hospitals - Anaheim, Long Beach, Orange Coast, and Saddleback Memorial Medical Centers - are located in Los Angeles and Orange Counties in Southern California in the United States. Additionally, birth certificate data were obtained for the four hospitals and the same study period from the California Department of Public Health [30].

\section{Data linkage}

Birth records from the Memorial Care System were matched to birth certificate records using fuzzy matching logic through the SAS "COMPGED" function, which measures the "generalized edit distance" that summarizes the degree of difference between two text strings - i.e. the number of deletions, insertions, or replacements in the characters of a word required to arrive at the observed word [31]. Memorial records were matched to birth certificate records according to their calculated degree of similarity based on different combinations of four variables: mother's first and last name, date of birth (DOB) of child, DOB of mother, and hospital of delivery. These variables were selected because they were the only variables available in both datasets that were specific enough to identify a particular birth. To maximize the matching rate, we conducted multiple matching procedures. Four variables were used in the matching process: DOB of child, hospital of delivery, DOB of mother, and mother's name. The following criteria by order of priority were used to compile the final dataset: 1) An exact match on all of the four variables, 2) An exact match on DOB of child, hospital of delivery, and mother's full name, but non-exact match on DOB of mother, 3) an exact match on DOB of child, hospital of delivery, and DOB of mother, but nonexact match on mother's name, and 4) an exact match on DOB of child and hospital of delivery, but non-exact match on both mother's name and $\mathrm{DOB}$ of mother. We assigned a partial match on DOB of mother if two of the three fields in the date of birth (i.e. year, month, day) were 
the same. We assumed a partial match on mother's name if the first three characters in both the first name and the last name of the mother were matched. There are respectively ten and three records with any missing values in the four matching variables in the Memorial and the birth certificate data, and they were excluded from the matching process.

\section{Data analysis}

We summarized the basic socio-demographic variables in both the Memorial and the birth certificate data and in the matched and the unmatched groups for each dataset. T-tests for continuous variables and chi-square tests for categorical variables were used for the comparisons of the rates of preeclampsia and diabetes, and the socio-demographic variables between the matched and the unmatched groups within each specific dataset.

Further, for the matched birth records, we compared the influence of socioeconomic factors (i.e. maternal education, race, and type of health insurance (private or public)) on the reported incidences of preeclampsia or diabetes during pregnancy. The Memorial data contained only the lumped variable of diabetes (gestational diabetes and pre-existing) during pregnancy. Prior to 2006, gestational and pre-existing diabetes were grouped into a single variable in the birth certificate data. After 2006, gestational diabetes and pre-existing diabetes were reported separately. Therefore, we analyzed diabetes over 2001-2005 and conducted sensitivity analysis using 2001-2006 data as well.

Given the potential for underreporting of adverse pregnancy outcomes on birth certificates, we did not specifically examine the agreement of the two databases using parameters such as sensitivity, specificity or Kappas.
Rather, we focused on determining if underreporting of diabetes and preeclampsia would disproportionately affect low socioeconomic status groups when level of maternal education, type of health insurance, and race were used as socioeconomic indicators. In order to explore this, we calculated the ratio of incidences of diabetes (both preexisting and gestational) and preeclampsia using birth certificate data compared to Memorial data. A permutation based statistical test was used to check whether the incidence of preeclampsia and diabetes was significantly underreported on birth certificate data when compared to Memorial data. The socioeconomic variables used for the comparison were those based on birth certificate data, which have been shown to provide reliable information on these variables [32-34]. Maternal education level was categorized as either high school or lower, or college or higher. Maternal race was categorized as Asian, Black, Hispanic, Non-Hispanic White, or Other, and insurance type was defined as either public or private.

\section{Results}

\section{Characteristics of study population}

After removing multiple births (e.g. twins and triplicates) and the records with missing matching variables, we obtained 66,352 and 71,512 records in the Memorial and the birth certificate data, respectively. After excluding these records, a total of 62,200 records ( $93.7 \%$ of Memorial data and $87.0 \%$ of birth certificate data) were matched and subsequently used in our analysis (Table 1). The exact match on all of the four variables accounted for $95 \%$ of all the matched records. Sensitivity analysis was conducted on the partial match on mother's name using different lengths of the sub-string of first and last names (from left to right: 2 to 15 characters). Since

Table 1 Matching rates based on different matching criteria

\begin{tabular}{|c|c|c|c|c|c|c|c|}
\hline & & & & & Number & $\begin{array}{l}\text { Percentage based on } \\
\text { Memorial Care data }\end{array}$ & $\begin{array}{l}\text { Percentage based on } \\
\text { birth certificate data }\end{array}$ \\
\hline \multicolumn{5}{|l|}{ Matched records } & 62200 & $85.79 \%$ & $86.98 \%$ \\
\hline & \multicolumn{4}{|c|}{ Matching Variables } & & & \\
\hline Types of matching & DOB of child & Delivery hospital & DOB of mother & Mother's name & & & \\
\hline $\begin{array}{l}\text { 1. Exact match on four } \\
\text { variables }\end{array}$ & Exact & Exact & Exact & Exact & 59105 & $81.52 \%$ & $82.65 \%$ \\
\hline $\begin{array}{l}\text { 2. Exact match on three } \\
\text { variables }\end{array}$ & Exact & Exact & Partial $^{a}$ & Exact & 2869 & $3.96 \%$ & $4.01 \%$ \\
\hline $\begin{array}{l}\text { 3. Exact match on three } \\
\text { variables }\end{array}$ & Exact & Exact & Exact & Partial $^{\text {b }}$ & 120 & $0.17 \%$ & $0.17 \%$ \\
\hline $\begin{array}{l}\text { 4. Exact match on two } \\
\text { variables }\end{array}$ & Exact & Exact & Partial $^{a}$ & Partial $^{b}$ & 106 & $0.15 \%$ & $0.15 \%$ \\
\hline \multicolumn{5}{|c|}{ Unmatched records in Memorial Care data with non-missing matching variables } & 4162 & $5.74 \%$ & \\
\hline \multicolumn{5}{|c|}{ Unmatched records in Memorial Care data with missing matching variables } & 6138 & $8.47 \%$ & \\
\hline \multicolumn{5}{|c|}{ Unmatched records in birth certificate data } & 9312 & & $13.02 \%$ \\
\hline
\end{tabular}

${ }^{a}$ matched by any two of the three fields: year, month, and day

${ }^{b}$ matched by the first three characters in both the first name and the last name of the mother 
the majority of records were matched by exact names, this only slightly changed the number of the final matched records (data not shown). Hence, we only reported the results based on the matching criteria listed above.

Summary statistics showed some differences in the characteristics of the study population between the Memorial and the birth certificate data and between the matched and unmatched records in each specific dataset (Table 2). The majority of women were between the ages of 30 and 39, had private health insurance, and had college or higher levels of education than did high school or lower (maternal education was only available on the birth certificate data). Hispanic and Non-Hispanic White made up the two largest categories in both the Memorial and the birth certificate data and in the unmatched and matched records in each dataset. Compared to the matched group, the unmatched groups on average had higher rates of preeclampsia and diabetes, were older, had lower educational attainment, and had a higher percentage of Hispanic women and a lower percentage of Non-Hispanic White and Black women in both the Memorial and the birth certificate datasets (Table 2). Since we had a large sample size $(N=4162$ to 62200$)$, the majority of t-tests and chisquare tests showed statistically significant results when comparing the matched and the unmatched group in each dataset. Nevertheless, the pattern of difference in the unmatched vs. matched group was consistent in the Memorial data and the birth certificate data.

\section{Preeclampsia: 2001-2006}

It was found that the birth certificate data significantly underreported the incidence of preeclampsia when compared to the Memorial data (1.38 \% vs. $3.13 \%$ ) (Table 2 ) $(p<0.01)$. The underreporting in birth certificate data was also observed in subcategories of the socioeconomic variables we examined.

\section{Percentage of preeclampsia by maternal education}

Of the mothers with known education level, the birth certificate data showed that the incidence of preeclampsia was significantly higher among mothers with education levels of college or higher compared with mothers with education levels of high school or lower $(1.46 \%$ vs. $1.24 \% ; p=0.02$ ) (Table 3). No difference was observed in the Memorial data. Nevertheless, the degree of underreporting of preeclampsia using birth certificate data compared to Memorial data was significantly higher among women with lower education levels $(p=0.01)$.

\section{Percentage of preeclampsia by race}

Both the Memorial and birth certificate data indicated the highest rate of preeclampsia in Black women (4.12 and $1.90 \%$, respectively) among the four major race/ethnicity categories. Within the Memorial data, Asian and Hispanic women had significantly lower rates of preeclampsia than Black women $(p<0.01)$. The same held true for the birth certificate data. In addition, Hispanic women had significantly lower rates of preeclampsia than Non-Hispanic White women $(p=0.03)$ in the birth certificate data, while Asian women had significantly lower rates of preeclampsia than Non-Hispanic White women $(p=0.01)$ in the Memorial data.

Compared to the Memorial data, the birth certificate data showed a significantly higher degree of underreporting of preeclampsia in Hispanic women compared to Non-Hispanic White women $(p=0.01)$. No significant difference for the degree of underreporting in birth certificate data was observed between the other race/ethnicity groups.

\section{Percentage of preeclampsia by insurance}

The Memorial data indicated a marginally significantly lower rate of preeclampsia in women with private insurance compared to those with public insurance (3.32\% vs. $3.02 \% ; p=0.05)$. A different but insignificant pattern was observed in the birth certificate data. Compared to the Memorial data, the birth certificate data showed a significantly higher degree of underreporting of preeclampsia within the public insurance group compared to the private insurance group $(p=0.02)$.

\section{Diabetes (2001-2005)}

Similar to preeclampsia, the birth certificate data significantly underreported the incidence of diabetes when compared to the Memorial data $(1.97 \%$ vs. $5.56 \%)$ (Table 2) $(p<0.01)$. Memorial data indicated that the incidence rate of diabetes during pregnancy was higher among women with lower socioeconomic status, but the pattern was insignificant in the birth certificate data. Sensitivity analysis showed similar results based on data in the 2001-2006 period (results not shown).

\section{Percentage of diabetes by maternal education}

No significant patterns were observed in birth certificate data. However, of the women whose educational level was known, the Memorial data indicated that the incidence of diabetes was significantly higher among women with levels of education of high school or lower compared to college or higher $(6.18 \%$ vs. $5.18 \% ; p<0.01)$ (Table 4). The birth certificate data showed a similar but insignificant pattern. Furthermore, the degree of underreporting of diabetes using birth certificate data compared to memorial data was significantly higher among women with lower education levels $(p=0.01)$. 
Table 2 Characteristics of the study population from Four Memorial Care Hospitals in Southern California

\begin{tabular}{|c|c|c|c|c|c|c|c|}
\hline & $\begin{array}{l}\text { Matched memorial } \\
\text { care data }\end{array}$ & $\begin{array}{l}\text { Unmatched Mer } \\
\text { Care data }\end{array}$ & Iorial & $p$-value ${ }^{*}$ & $\begin{array}{l}\text { Matched birth } \\
\text { certificate data }\end{array}$ & $\begin{array}{l}\text { Unmatched birth } \\
\text { certificate data }\end{array}$ & $p$-value \\
\hline & & $\begin{array}{l}\text { Valid matching } \\
\text { variables }\end{array}$ & $\begin{array}{l}\text { Missing matching } \\
\text { variables }\end{array}$ & & & $\begin{array}{l}\text { Valid matching } \\
\text { variables }^{\mathrm{a}}\end{array}$ & \\
\hline N & 62200 & 4162 & 6138 & & 62200 & 9312 & \\
\hline $\begin{array}{l}\text { Rate of preeclampsia } \\
\text { (2001-2006 data) }\end{array}$ & 3.13 & 3.73 & 4.12 & $<0.01$ & 1.38 & 1.97 & $<0.01$ \\
\hline $\begin{array}{l}\text { Rate of preeclampsia } \\
\text { (2001-2005 data) }\end{array}$ & 3.12 & 3.70 & 4.12 & $<0.01$ & 1.34 & 1.75 & $<0.01$ \\
\hline $\begin{array}{l}\text { Rate of preeclampsia } \\
\text { (2006 data only) }\end{array}$ & 3.13 & 3.90 & N.A. & 0.41 & 1.57 & 2.23 & $<0.01$ \\
\hline $\begin{array}{l}\text { Rate of total diabetes } \\
\text { (2001-2005 data) }\end{array}$ & 5.56 & 6.65 & 5.46 & 0.17 & 1.97 & 2.11 & 0.40 \\
\hline $\begin{array}{l}\text { Rate of total diabetes } \\
\text { (2006 data only) }\end{array}$ & 6.93 & 7.20 & N.A. & 0.35 & 2.24 & 3.67 & $<0.01$ \\
\hline $\begin{array}{l}\text { Rate of gestational diabetes } \\
\text { (2006 data only) }\end{array}$ & N.A. & N.A. & N.A. & & 1.62 & 2.57 & 0.01 \\
\hline $\begin{array}{l}\text { Rate of chronic diabetes } \\
\text { (2006 data only) }\end{array}$ & N.A. & N.A. & N.A. & & 0.62 & 1.10 & 0.04 \\
\hline Maternal age ${ }^{\mathrm{b}}(\%)$ & & & & $<0.01$ & & & $<0.01$ \\
\hline$<20$ & 6.62 & 5.77 & N.A. & & 6.62 & 5.76 & \\
\hline $20-29$ & 42.38 & 39.60 & N.A. & & 42.44 & 39.79 & \\
\hline $30-39$ & 46.75 & 47.57 & N.A. & & 46.77 & 48.41 & \\
\hline $40+$ & 4.18 & 6.78 & N.A. & & 4.16 & 6.04 & \\
\hline Unknown & 0.07 & 0.29 & N.A. & & 0.00 & 0.00 & \\
\hline $\begin{array}{l}\text { Maternal age }{ }^{\mathrm{b}} \text { (years): } \\
\text { mean } \pm \text { standard deviation }\end{array}$ & $29.79 \pm 6.17$ & $30.56 \pm 6.46$ & N.A. & $<0.01$ & $29.78 \pm 6.16$ & $30.44 \pm 6.34$ & $<0.01$ \\
\hline Maternal education (\%) & & & & & & & $<0.01$ \\
\hline College or higher & N.A. & N.A. & N.A. & & 57.26 & 52.71 & \\
\hline High school or lower & N.A. & N.A. & N.A. & & 40.82 & 43.93 & \\
\hline Unknown & N.A. & N.A. & N.A. & & 1.92 & 3.36 & \\
\hline Race/ethnicity ${ }^{\mathrm{b}}(\%)$ & & & & $<0.01$ & & & $<0.01$ \\
\hline Asian & 10.49 & 9.61 & N.A. & & 13.65 & 14.85 & \\
\hline Black & 8.47 & 6.68 & N.A. & & 8.96 & 6.20 & \\
\hline Hispanic & 33.01 & 42.74 & N.A. & & 36.97 & 39.42 & \\
\hline Non-Hispanic White & 39.62 & 30.56 & N.A. & & 37.62 & 35.72 & \\
\hline Other & 4.52 & 5.00 & N.A. & & 1.91 & 1.98 & \\
\hline Unknown & 3.88 & 5.41 & N.A. & & 0.89 & 1.84 & \\
\hline Insurance ${ }^{\mathrm{b}}(\%)$ & & & & $<0.01$ & & & $<0.01$ \\
\hline Private & 65.95 & 57.81 & N.A. & & 66.77 & 66.91 & \\
\hline Public & 29.97 & 35.66 & N.A. & & 32.69 & 32.25 & \\
\hline Other & 0.00 & 0.00 & N.A. & & 0.44 & 0.63 & \\
\hline Unknown & 4.07 & 6.54 & N.A. & & 0.11 & 0.20 & \\
\hline
\end{tabular}

${ }^{*} p$-value for the comparison between the matched Memorial Care and the unmatched Memorial Care data with valid matching variables

** $p$-value for the comparison between the matched birth certificate data and the unmatched birth certificate data (all had valid matching variables)

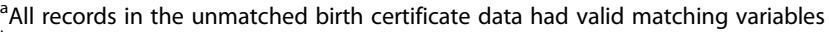

${ }^{\text {b } B o t h ~ d a t a b a s e s ~ h a v e ~ r e p o r t e d ~ v a l u e s ~ f o r ~ t h e s e ~ v a r i a b l e s . ~ I n ~ t h i s ~ t a b l e, ~ w e ~ c a l c u l a t e d ~ t h e ~ s t a t i s t i c ~ s u m m a r i e s ~ b a s e d ~ o n ~ t h e ~ v a l u e s ~ r e p o r t e d ~ i n ~ e a c h ~ s p e c i f i c ~ d a t a b a s e ~}$

Percentage of diabetes by race

The birth certificate data found that the incidence of diabetes was highest among Asian women (2.65 \%) and lowest among Non-Hispanic White women (1.54 \%), while the Memorial data indicated the highest incidence rate among women of race/ethnicities classified as "other" 
Table 3 Incidence rate of preeclampsia (2001-2006) by socioeconomic indicators

\begin{tabular}{|c|c|c|c|c|c|}
\hline & & Number & $\begin{array}{l}\text { Incidence rate: } \\
\text { Memorial data }\end{array}$ & $\begin{array}{l}\text { Incidence rate: birth } \\
\text { certificate data }\end{array}$ & $\begin{array}{l}\text { Ratio of incidence rate: birth } \\
\text { certificate/Memorial data }\end{array}$ \\
\hline \multirow[t]{4}{*}{ Maternal Education ${ }^{a}$} & College or higher & 35616 & $3.11 \%$ & $1.46 \%$ & 0.47 \\
\hline & High School or lower & 25389 & $3.17 \%$ & $1.24 \%$ & 0.39 \\
\hline & Unknown & 1195 & $2.76 \%$ & $2.01 \%$ & 0.73 \\
\hline & $\begin{array}{l}\text { p-value: College or higher vs. } \\
\text { High school or lower }\end{array}$ & & 0.65 & $0.02^{*}$ & $0.01^{*}$ \\
\hline \multirow[t]{10}{*}{ Race/ethnicity ${ }^{a}$} & Asian & 8489 & $2.67 \%$ & $1.06 \%$ & 0.40 \\
\hline & Black & 5576 & $4.12 \%$ & $1.90 \%$ & 0.46 \\
\hline & Hispanic & 22995 & $3.20 \%$ & $1.25 \%$ & 0.39 \\
\hline & Non-Hispanic White & 23400 & $2.95 \%$ & $1.48 \%$ & 0.50 \\
\hline & Other & 1187 & $4.13 \%$ & $1.52 \%$ & 0.37 \\
\hline & Unknown & 553 & $2.35 \%$ & $1.81 \%$ & 0.77 \\
\hline & $p$-value: Asian-Black & & $0.00^{*}$ & $0.00^{*}$ & 0.20 \\
\hline & p-value: Asian-Hispanic & & $0.01^{*}$ & 0.15 & 0.48 \\
\hline & p -value: Black-Hispanic & & $0.00^{*}$ & $0.00^{*}$ & 0.15 \\
\hline & p -value: Hispanic- NH White & & 0.12 & $0.03^{*}$ & $0.01^{*}$ \\
\hline \multirow[t]{5}{*}{ Insurance ${ }^{a}$} & Private & 41024 & $3.02 \%$ & $1.46 \%$ & 0.48 \\
\hline & Public & 18643 & $3.32 \%$ & $1.30 \%$ & 0.39 \\
\hline & Other & 2527 & $3.44 \%$ & $0.79 \%$ & 0.23 \\
\hline & Unknown & 6 & $0.00 \%$ & $0.00 \%$ & N.A. \\
\hline & $p$-value: Private vs. Public & & 0.05 & 0.12 & $0.02^{*}$ \\
\hline
\end{tabular}

${ }^{a}$ The classification of socioeconomic status was based on variables reported in the birth certificate data

*Statistically significant result at an alpha level of 0.05

(8.19\%) and Asian (7.41 \%) and lowest among NonHispanic White women (3.63\%). For both the Memorial and birth certificate data, the difference in incidence rates was significant $(p<0.01)$ between all the race/ethnicity group pairs except Asian and Hispanics. Furthermore, the degree of underreporting using birth certificate data compared to Memorial data was significantly higher among Hispanic women compared to Non-Hispanic White women $(p<0.01)$.

\section{Percentage of diabetes by insurance}

Memorial data found that the incidence of diabetes was significantly higher among women with public health insurance compared to women with private health insurance $(6.25 \%$ vs. $5.25 \%, p<0.01)$. The birth certificate data showed a similar but insignificant pattern. The degree of underreporting of diabetes using birth certificate data compared to Memorial data was significantly higher among women with public insurance compared to those with private insurance $(p=0.05)$.

\section{Discussion}

We found that the birth certificate data that was analyzed significantly underreported the incidences of preeclampsia and diabetes compared to the Memorial data, which was collected specifically for research purposes. In addition, the degree of underreporting was disproportionately distributed across groups of different socioeconomic status, with certain socioeconomic indicators exhibiting higher degrees of underreporting.

The degree of underreporting of both preeclampsia and diabetes using birth certificate data was significantly higher women with lower education levels compared to women with higher levels of education, in Hispanic women compared to non-Hispanic White women, in women with public insurance compared to those with private insurance. These results indicate a disparate underreporting problem in low socioeconomic groups for pregnancy complications when race, level of education, and insurance status are used as socioeconomic indicators.

Several reasons may exist to explain the discrepancies between our two datasets, such as the weaknesses of birth certificate data discovered by several other studies. These include inadequate auditing of birth certificate data by individual hospitals, variations in data collection, diagnosis, and reporting procedures across hospitals, the use of nonclinical or untrained personnel to record data, and budgetary restrictions that prevent state agencies from thoroughly assessing and ensuring the quality of 
Table 4 Incidence rate of diabetes (2001-2005) by socioeconomic indicators

\begin{tabular}{|c|c|c|c|c|c|}
\hline & & Number & $\begin{array}{l}\text { Incidence rate: } \\
\text { Memorial data }\end{array}$ & $\begin{array}{l}\text { Incidence rate: birth } \\
\text { certificate data }\end{array}$ & $\begin{array}{l}\text { Ratio of incidence rate: birth } \\
\text { certificate/Memorial data }\end{array}$ \\
\hline \multirow[t]{4}{*}{ Maternal Education ${ }^{a}$} & College or higher & 29653 & $5.18 \%$ & $1.95 \%$ & 0.38 \\
\hline & High School or lower & 20917 & $6.18 \%$ & $2.01 \%$ & 0.32 \\
\hline & Unknown & 973 & $3.49 \%$ & $1.75 \%$ & 0.50 \\
\hline & $\begin{array}{l}\text { p-value: College or higher vs. } \\
\text { High school or lower }\end{array}$ & & $0.00^{*}$ & 0.66 & $0.01^{*}$ \\
\hline \multirow[t]{10}{*}{ Race/ethnicity ${ }^{\mathrm{a}}$} & Asian & 6897 & $7.41 \%$ & $2.65 \%$ & 0.36 \\
\hline & Black & 4561 & $4.93 \%$ & $1.67 \%$ & 0.34 \\
\hline & Hispanic & 18755 & $6.95 \%$ & $2.24 \%$ & 0.32 \\
\hline & Non-Hispanic White & 19856 & $3.63 \%$ & $1.54 \%$ & 0.42 \\
\hline & Other & 965 & $8.19 \%$ & $2.38 \%$ & 0.29 \\
\hline & Unknown & 509 & $4.52 \%$ & $1.77 \%$ & 0.39 \\
\hline & $p$-value: Asian-Black & & $0.00^{*}$ & $0.00^{*}$ & 0.35 \\
\hline & p-value: Asian-Hispanic & & 0.21 & 0.06 & 0.15 \\
\hline & p -value: Black-Hispanic & & $0.00^{*}$ & $0.01^{*}$ & 0.37 \\
\hline & p -value: Hispanic- NH White & & $0.00^{*}$ & $0.00^{*}$ & $0.00^{*}$ \\
\hline \multirow[t]{5}{*}{ Insurance ${ }^{a}$} & Private & 34489 & $5.25 \%$ & $1.95 \%$ & 0.37 \\
\hline & Public & 15034 & $6.25 \%$ & $2.02 \%$ & 0.32 \\
\hline & Other & 2015 & $5.56 \%$ & $1.94 \%$ & 0.35 \\
\hline & Unknown & 5 & $0.00 \%$ & $0.00 \%$ & N.A. \\
\hline & $p$-value: Private vs. Public & & $0.00^{*}$ & 0.61 & $0.05^{*}$ \\
\hline
\end{tabular}

${ }^{a}$ The classification of socioeconomic status was based on variables reported in the birth certificate data

*Statistically significant result at an alpha level of 0.05

birth certificate data $[8,10,35-38]$. The Memorial data, in turn, may have had better quality on pregnancy complications because it was a research database that underwent more stringent quality checks by nurses. Although the Memorial database is not a gold standard, it is believed that it is more accurate than birth certificate data because information is recorded when patients are physically present and able to verify records.

We attempted to maximally match the Memorial and birth certificate records. However, there were still $8.47 \%$ and $5.74 \%$ of the Memorial records that could not be matched to the birth certificates due to missing matching variables (i.e. mother's name and mother's date of birth) and likely moderate to serious problems in misspelling of the names, respectively. We found differences in the matched and unmatched groups in the rates of preeclampsia and diabetes and in socio-demographic parameters. But since the patterns of difference in the matched and the unmatched groups was consistent between the Memorial data and the birth certificate data, we do not expect it to change our main conclusion of the underreporting problem in the birth certificate data.

Since the Memorial data did not differentiate between gestational diabetes and diabetes when reporting pregnancy outcomes, it was not possible to investigate gestational diabetes specifically in this study. However, because the birth certificate data began reporting gestational diabetes separately starting in 2006, we were able to perform two separate analyses on diabetes using 2001-2005 and 2001-2006 as periods of interest. Both periods showed the same patterns of underreporting of diabetes, and we thus suspect that our findings on total diabetes likely hold for gestational diabetes as well. It has been estimated that approximately $90 \%$ of pregnancies that are complicated by diabetes mellitus represent women with gestational diabetes mellitus [39]. In the 2006 birth certificate data in California, we observed that gestational diabetes accounted for $72 \%$ of the total diabetes (Table 2). This high degree of overlap between gestational diabetes and diabetes during pregnancy further suggests that the findings of this study regarding diabetes in general may also be applicable to cases of gestational diabetes in particular.

These results are consistent with previous studies, particularly those that determined that birth certificates are not reliable sources of information regarding preeclampsia, gestational diabetes, and other maternal complications and characteristics, particularly when compared to 
hospital discharge records [7-11]. Thus, our conclusion that the birth certificate database used in this study underreported the incidence of preeclampsia and gestational diabetes is supported by similar patterns found elsewhere in the United States. However, to our knowledge this is the first study to assess the reliability of hospital data and birth certificates in southern California, and the first to address differential reporting of preeclampsia and diabetes during pregnancy by socioeconomic status in the United States.

The socioeconomic differences seen in the underreporting of preeclampsia and gestational diabetes as specific outcomes of interest is a unique observation that has not been studied in southern California. However, similar results have been found by studies that have analyzed related, though not identical, variables elsewhere in the United States. Most notably, a study on the sensitivity of birth certificate reports of birth defects in Atlanta found that Non-Hispanic Black maternal race/ethnicity and maternal education levels lower than high school were independently associated with a lower probability of a birth defect diagnosis being reported on a birth certificate [9]. The authors of this study hypothesized that this observation might be explained by disparities in access to healthcare, as well as variations in personnel and birth certificate completion procedures across hospitals. Although our study did not analyze birth defects, the underreporting of adverse pregnancy outcomes we found according to racial and education level factors followed a similar pattern and can be explained by the same observations.

Further research must be performed to elucidate an explanation for the poor reliability of this particular set of birth certificate data for pregnancy complications, as well as the observed socioeconomic gradient in underreporting of such outcomes. Nevertheless, these findings have important implications for future public health research. Studies that rely solely on birth certificate data to draw conclusions regarding pregnancy complications should be aware of a potential bias towards underestimating the incidence of these conditions, particularly in low socioeconomic groups. This is critical for the descriptive study of socioeconomic disparities in pregnancy complications, and might contribute to explain why discrepant results were reported in the past [17-28], beside any true difference in disparities across study settings. Such biases are also critical for etiologic research studying the relationships between pregnancy complications and potential risk factors, especially when these are unevenly distributed according to socioeconomic status. For instance, exposure to most air pollutants (e.g., primary particles from road traffic) is typically higher in populations with low socioeconomic status than in better-off ones [40, 41]. In such a situation, a higher underreporting of maternal complications in populations with lower socioeconomic status would create a downward bias while measuring the association between air pollution and pregnancy complications. Consequently, researchers should attempt to use high quality health outcome data such as the Memorial database, either in place of or in conjunction with birth certificate data, whenever possible in order to minimize bias.

Furthermore, these findings indicate that there is a considerable need to improve the quality of birth certificate data in California, as far as pregnancy complications are concerned. There is a possibility that the quality of birth certificate has improved since 2006, the last year of this analysis. It would be beneficial to assess the quality of current birth certificate data in order to identify areas that still require improvement. However, historical birth certificate data are still of high importance for research studies that examine the impact of in-utero exposure on various long-term health effects (e.g. cognition and school performance in children, obesity, cardiovascular diseases etc.). Standardizing data collection and reporting procedures across hospitals would help minimize the discrepancies seen between birth certificate data and hospital databases such as the Memorial database. Because diabetes and preeclampsia are conditions that are oftentimes diagnosed prior to delivery and not at the hospital of delivery, there is also a need to improve the integration of prior medical records from other sources with hospital and birth certificate records. What is more, the fact that the birth certificate data underreported both preeclampsia and diabetes and did so to a higher degree among groups of lower socioeconomic status suggests that it would be most effective to focus standardization efforts on these particular conditions and among these identified groups, including Black and Hispanic women, women with lower levels of education, and women with public insurance. Finally, the most disadvantaged women may not have access to health care; thus improving health care access for low-income and minority people may also improve the reporting of pregnancy complications.

\section{Conclusion}

In summary, this comparison of two birth record databases found that the Memorial database is a more reliable source of information than birth certificate data for analyzing the incidence of preeclampsia and gestational diabetes among women in Los Angeles County. This is especially true for subpopulations of lower socioeconomic status. Efforts to improve the available sources of data for the study of adverse pregnancy outcomes should thus focus on improving the reliability of birth certificate data, particularly for women of lower socioeconomic status. 


\section{Declarations}

\section{Ethics and consent}

The study has been approved by the Institutional Review Board of the University of California, Irvine and by the Institutional Review Board of MemorialCare Health System and Long Beach Memorial Medical Center. However, informed consent from study participants was not required because the nature of the study was analysis of existing data, which posed minimal risk to the subjects. In addition, it was not practically feasible to contact all the subjects.

\section{Consent to publish \\ Not applicable.}

\section{Availability of data and materials}

The birth record data used in this study will not be shared because they contained confidential information including the name of the mother and the date of birth of both the mother and the infant.

\section{Abbreviation}

DOB: date of birth

\section{Competing interests}

The authors declare that they have no competing interests.

\begin{abstract}
Authors' contributions
JW conceived the study, designed the methods, conducted part of the analyses in the first draft and most of the analyses in the revision. $\mathrm{NH}$ helped with the analyses and drafted the manuscript. $\mathrm{MH}$ and $\mathrm{OL}$ contributed to methods and data analysis. JC retrieved hospital-based birth record data. PN helped with literature review. All authors contributed to the interpretation of data and edited various sections of the manuscript. All authors read and approved the final manuscript.
\end{abstract}

\section{Acknowledgments}

The authors thank the staff at the MemorialCare Health System and the California Department of Health for their help in retrieving the birth record data.

\section{Funding}

The study was supported by the Health Effect Institute (HEI 4787-RFA094110-3 WU).

\section{Author details}

${ }^{1}$ Program in Public Health, College of Health Sciences, University of California, Anteater Instruction \& Research BIdg (AIRB) \# 2034, 653 East Peltason Drive, Irvine, CA 92697-3957, USA. ${ }^{2}$ Maternal-Fetal Medicine, School of Medicine, University of California, Irvine, CA, USA. ${ }^{3}$ VA Long Beach Healthcare System, Long Beach, CA, USA.

Received: 30 September 2015 Accepted: 21 April 2016

Published online: 27 April 2016

\section{References}

1. Committee on Practice B-O. Practice Bulletin No. 137: Gestational diabetes mellitus. Obstet Gynecol. 2013;122(2 Pt 1):406-16.

2. Chen Y, Quick WW, Yang W, Zhang Y, Baldwin A, Moran J, et al. Cost of gestational diabetes mellitus in the United States in 2007. Popul Health Manag. 2009:12(3):165-74.

3. DeSisto CL, Kim SY, Sharma AJ. Prevalence estimates of gestational diabetes mellitus in the United States, Pregnancy Risk Assessment Monitoring System (PRAMS), 2007-2010. Prev Chronic Dis. 2014;11:E104.
4. Hunt KJ, Schuller KL. The increasing prevalence of diabetes in pregnancy. Obstet Gynecol Clin North Am. 2007;34(2):173-99. vii.

5. Coghill AE, Hansen S, Littman AJ. Risk factors for eclampsia: a populationbased study in Washington State, 1987-2007. Am J Obstet Gynecol. 2011;205(6):553. e551-557.

6. Ananth $\mathrm{CV}$, Keyes KM, Wapner RJ. Pre-eclampsia rates in the United States, 1980-2010: age-period-cohort analysis. BMJ. 2013;347:f6564.

7. Lydon-Rochelle MT, Holt VL, Cardenas V, Nelson JC, Easterling TR, Gardella C, et al. The reporting of pre-existing maternal medical conditions and complications of pregnancy on birth certificates and in hospital discharge data. Am J Obstet Gynecol. 2005;193(1):125-34.

8. DiGiuseppe DL, Aron DC, Ranbom L, Harper DL, Rosenthal GE. Reliability of birth certificate data: a multi-hospital comparison to medical records information. Matern Child Health J. 2002;6(3):169-79.

9. Boulet SL, Shin M, Kirby RS, Goodman D, Correa A. Sensitivity of birth certificate reports of birth defects in Atlanta, 1995-2005: effects of maternal, infant, and hospital characteristics. Public Health Rep. 2011;126(2):186-94.

10. Piper JM, Mitchel EF Jr, Snowden M, Hall C, Adams M, Taylor P. Validation of 1989 Tennessee birth certificates using maternal and newborn hospital records. Am J Epidemiol. 1993;137(7):758-68.

11. Northam S, Knapp TR. The reliability and validity of birth certificates. J Obstet Gynecol Neonatal Nurs. 2006;35(1):3-12.

12. Bilano VL, Ota E, Ganchimeg T, Mori R, Souza JP. Risk factors of pre-eclampsia/eclampsia and its adverse outcomes in low- and middleincome countries: a WHO secondary analysis. PLoS One. 2014;9(3):e91198.

13. Coonrod DV, Hickok DE, Zhu K, Easterling TR, Daling JR. Risk factors for preeclampsia in twin pregnancies: a population-based cohort study. Obstet Gynecol. 1995:85(5 Pt 1):645-50.

14. Parazzini F, Bortolus R, Chatenoud L, Restelli S, Ricci E, Marozio L, et al. Risk factors for pregnancy-induced hypertension in women at high risk for the condition. Italian Study of Aspirin in Pregnancy Group. Epidemiology. 1996; 7(3):306-8.

15. Savitz DA, Zhang J. Pregnancy-induced hypertension in North Carolina, 1988 and 1989. Am J Public Health. 1992;82(5):675-9.

16. Sibai BM, Gordon T, Thom E, Caritis SN, Klebanoff M, McNellis D, et al. Risk factors for preeclampsia in healthy nulliparous women: a prospective multicenter study. The National Institute of Child Health and Human Development Network of Maternal-Fetal Medicine Units. Am J Obstet Gynecol. 1995;172(2 Pt 1):642-8.

17. Bo S, Menato G, Bardelli C, Lezo A, Signorile A, Repetti E, et al. Low socioeconomic status as a risk factor for gestational diabetes. Diabetes Metab. 2002;28(2):139-40.

18. Clausen T, Oyen N, Henriksen T. Pregnancy complications by overweight and residential area. A prospective study of an urban Norwegian cohort. Acta Obstet Gynecol Scand. 2006:85(5):526-33.

19. Schneider S, Hoeft B, Freerksen N, Fischer B, Roehrig S, Yamamoto S, et al. Neonatal complications and risk factors among women with gestational diabetes mellitus. Acta Obstet Gynecol Scand. 2011;90(3):231-7.

20. AlKasseh AS, Zaki NM, Aljeesh YI, Soon LK. Risk factors of gestational diabetes mellitus in the refugee population in Gaza Strip: a case-control study. East Mediterr Health J. 2014;19 Suppl 3:S12-8.

21. Dode MA, Santos IS. Risk factors for gestational diabetes mellitus in the birth cohort in Pelotas, Rio Grande do Sul State, Brazil, 2004. Cad Saúde Pública. 2009;25(5):1141-52.

22. Berkowitz GS, Lapinski RH, Wein R, Lee D. Race/ethnicity and other risk factors for gestational diabetes. Am J Epidemiol. 1992;135(9):965-73.

23. Cullinan J, Gillespie P, Owens L, Avalos G, Dunne F. Is there a socioeconomic gradient in the prevalence of gestational diabetes mellitus? Ir Med J. 2012:105(5 Suppl):21-3.

24. Joseph KS, Liston RM, Dodds L, Dahlgren L, Allen AC. Socioeconomic status and perinatal outcomes in a setting with universal access to essential health care services. CMAJ. 2007:177(6):583-90.

25. Khan R, Ali K, Khan Z. Socio-demographic Risk Factors of Gestational Diabetes Mellitus. Pak J Med Sci. 2013:29(3):843-6.

26. Janghorbani M, Stenhouse E, Jones R, Millward B. Is neighbourhood deprivation a risk factor for gestational diabetes mellitus? Diabet Med. 2006; 23(3):313-7.

27. Brown HL, Chireau MV, Jallah Y, Howard D. The "Hispanic paradox": an investigation of racial disparity in pregnancy outcomes at a tertiary care medical center. Am J Obstet Gynecol. 2007;197(2):197. e191-197; discussion 197 e197-199. 
28. Bertolotto A, Corfini M, Ghio A, Resi V, Lencioni C, Lacaria E, et al. Is maternal educational level a risk factor for gestational diabetes in Caucasian women? Diabet Med. 2012;29(3):416-7.

29. Wu J, Ren C, Delfino RJ, Chung J, Wilhelm M, Ritz B. Association between local traffic-generated air pollution and preeclampsia and preterm delivery in the south coast air basin of California. Environ Health Perspect. 2009;117(11):1773-9.

30. Laurent O, Hu J, Li L, Cockburn M, Escobedo L, Kleeman MJ, et al. Sources and contents of air pollution affecting term low birth weight in Los Angeles County, California, 2001-2008. Environ Res. 2014;134:488-95.

31. Staum P. Fuzzy Matching using the COMPGED Function In: North East SAS Users Group: 2007; West Nyack, NY: Paul Waldron Consulting.

32. Baumeister L, Marchi K, Pearl M, Williams R, Braveman P. The validity of information on "race" and "Hispanic ethnicity" in California birth certificate data. Health Serv Res. 2000:35(4):869-83.

33. Vinikoor LC, Messer LC, Laraia BA, Kaufman JS. Reliability of variables on the North Carolina birth certificate: a comparison with directly queried values from a cohort study. Paediatr Perinat Epidemiol. 2010;24(1):102-12.

34. Braveman P, Pearl M, Egerter S, Marchi K, Williams R. Validity of insurance information on California birth certificates. Am J Public Health. 1998;88(5):813-6.

35. Watkins ML, Edmonds L, McClearn A, Mullins L, Mulinare J, Khoury M. The surveillance of birth defects: the usefulness of the revised US standard birth certificate. Am J Public Health. 1996;86(5):731-4.

36. Dobie SA, Baldwin LM, Rosenblatt RA, Fordyce MA, Andrilla CH, Hart LG. How well do birth certificates describe the pregnancies they report? The Washington State experience with low-risk pregnancies. Matern Child Health J. 1998;2(3):145-54.

37. Kirby RS. The quality of data reported on birth certificates. Am J Public Health. 1997;87(2):301.

38. Starr P, Starr S. Reinventing vital statistics. The impact of changes in information technology, welfare policy, and health care. Public Health Rep. 1995:110(5):534-44.

39. Wier L, Witt E, Burgess J, Elixhauser A. Hospitalizations related to diabetes in pregnancy, 2008: statistical brief\# 102. 2006

40. Bell ML, Ebisu K. Environmental inequality in exposures to airborne particulate matter components in the United States. Environ Health Perspect. 2012;120(12):1699-704.

41. Tian N, Xue J, Barzyk TM. Evaluating socioeconomic and racial differences in traffic-related metrics in the United States using a GIS approach. J Expo Sci Environ Epidemiol. 2013;23(2):215-22.

\section{Submit your next manuscript to BioMed Central and we will help you at every step:}

- We accept pre-submission inquiries

- Our selector tool helps you to find the most relevant journal

- We provide round the clock customer support

- Convenient online submission

- Thorough peer review

- Inclusion in PubMed and all major indexing services

- Maximum visibility for your research

Submit your manuscript at wuw biomedcentral.com/submit

) Biomed Central 